\title{
BMJ Global Health Inequities in the global representation of sites participating in large, multicentre dialysis trials: a systematic review
}

\author{
Brendan Smyth (D) , ${ }^{1,2}$ Konlawij Trongtrakul, ${ }^{3}$ Anna Haber, ${ }^{4}$ B Talbot, ${ }^{1}$ \\ Carmel Hawley, ${ }^{5,6}$ Vlado Perkovic, ${ }^{1}$ Mark Woodward, ${ }^{7,8}$ Meg Jardine ${ }^{1,9}$
}

\begin{abstract}
To cite: Smyth B, Trongtrakul K, Haber $\mathrm{A}$, et al. Inequities in the global representation of sites participating in large, multicentre dialysis trials: a systematic review. BMJ Global Health 2019;4:e001940. doi:10.1136/ bmjgh-2019-001940
\end{abstract}

Handling editor Seye Abimbola

- Additional material is published online only. To view, please visit the journal online (http://dx.doi.org/10.1136/ bmjgh-2019-001940).

Received 26 August 2019 Revised 18 October 2019 Accepted 19 0ctober 2019

Check for updates

(c) Author(s) (or their employer(s)) 2019. Re-use permitted under CC BY-NC. No commercial re-use. See rights and permissions. Published by BMJ.

For numbered affiliations see end of article.

Correspondence to

Dr Brendan Smyth;

bsmyth@georgeinstitute.org.au

\section{ABSTRACT}

Background The number of dialysis recipients is growing worldwide, making it important that the full range of patient populations are represented in randomised trials. As trial recruitment has not previously been examined at a global level, we compared the location of trial sites recruiting to large multicentre randomised controlled trials (RCTs) in dialysis to the global distribution of dialysis recipients.

Methods A systematic review (2007-2016) was conducted to identify RCTs enrolling $\geq 100$ dialysis patients from $\geq 2$ sites. The number and location of sites were extracted from manuscripts and trial registration. The proportion of sites from each International Society of Nephrology global region was divided by the proportion of the global dialysis population in that region to determine a 'representation index' (RI), where 1.0 indicated that the number of sites was proportionate to the number of dialysis recipients in that region.

Results We identified 180 RCTs, recruiting from 6172 sites in 54 countries. Eastern and Central Europe had the highest $\mathrm{Rl}$ at 2.45. Other well-represented regions were Western Europe (2.20), North America (2.06), and Russia and newly independent states (1.36). Africa had the lowest $\mathrm{Rl}$ at 0.05 , followed by South Asia (0.08), Latin America (0.15), Middle East (0.27), North-East Asia (0.41), and South-East Asia and Oceania (0.62).

Conclusions Regions of the world with growing numbers of dialysis patients are poorly represented in large, multicentre RCTs. Efforts to boost trial participation in these regions are required to ensure that generalisable and relevant information is available to local healthcare providers.

\section{INTRODUCTION}

By 2030, over 5 million people around the world are expected to be receiving kidney replacement therapy (KRT) for end-stage kidney disease (ESKD), with much of the growth to come from regions outside of Europe and North America. ${ }^{1}$ The majority of these individuals will receive dialysis

\section{Key questions}

What is already known?

- The number of people receiving renal replacement therapy (mainly dialysis) for end-stage kidney disease (ESKD) is already over 2.5 million and is expected to exceed 5 million within a decade.

- Yet, no systematic global description of the participation of treatment centres in large, multicentre randomised clinical trials has ever been undertaken.

\section{What are the new findings?}

- Enormous disparities in randomised research participation around the globe exist, with relative site representation being as low as $5 \%$ what would be expected from the number of dialysis recipients alone.

- Moreover, global regions with growing dialysis populations, especially in Asia and Africa, remain markedly under-represented.

\section{What do the new findings imply?}

- Clinicians, guideline writers and policymakers in under-represented regions should be alert to the potential challenges of generalising the results of key randomised trials to their local populations.

- The nephrology community should strive to build research networks to foster relevant clinical research, including clinicians and participants from regions facing a growing burden of ESKD.

(whether haemo- or peritoneal), resulting in a growing diversity of dialysis populations defined by differing patient characteristics, health system practices and resource availability. These differences ought to be reflected in the available clinical evidence as therapies proven to work in one context may be unavailable, or less effective, in another. Moreover, while many aspects of dialysis therapy and evidence are universally relevant, many clinical questions differ in importance to patients, clinicians and healthcare providers, 
depending on their location, available resources and context. $^{2}$

Randomised controlled trials (RCTs) play an essential role in advancing clinical knowledge and improving patient care, yet for their results to be applied, they must have a reasonable degree of external validity (or generalisability). ${ }^{3}$ Generalisable trials tend to enrol a larger number of participants from multiple sites to ensure that the intervention can be seen to work in a range of patients and settings. Such trials are, therefore, critically important to clinicians, healthcare providers and health economists when making patient treatment and resourceallocation decisions. Unfortunately, despite rapid growth in the burden of non-communicable diseases, the output of RCTs from low-income and middle-income countries is believed to be meagre. ${ }^{2}$ There has, however, been little formal study of this issue in nephrology. In this context, we hypothesised that, despite the global growth in dialysis recipients, low-middle-income countries would be poorly represented in recruitment to large, potentially generalisable dialysis trials. To test this hypothesis, we systematically reviewed large dialysis RCTs and compared trial participant recruitment to a number of dialysis patients in each of the 10 International Society of Nephrology (ISN) global regions.

\section{METHODS}

A systematic search of MEDLINE, PubMed and the Cochrane Central Register of Controlled Trials was conducted for RCTs that had enrolled at least 100 participants from at least two sites, with participants who were on maintenance dialysis for ESKD at the time of randomisation. Studies published between 01 January 2007 and 31 December 2016 were included. Studies were excluded if they enrolled participants aged $<18$ years, with acute kidney injury, or with or about to receive a kidney transplant. No language restrictions were applied. No definition of 'site' was made a priori, and the number of sites was determined according to each study author's description.

After removal of duplicates, titles and abstracts were screened independently by two of the three lead researchers (BS, AH and KT) for inclusion and exclusion criteria. Discrepancies between the two primary researchers were adjudicated by the third. Where multiple publications relating to the same trial cohort were identified, the earliest published manuscript was selected to be the primary source of information, such that no trial cohort could be counted more than once.

Data from each included study were then independently extracted by two researchers using a purpose-built online case report form. Material from supplementary online appendices, secondary publications and online trial registration information was also accessed, if necessary, to ascertain the required information. Discrepancies in extracted data were resolved by discussion among the researchers.
Extracted data items included the number of randomised participants, number of sites (centres could be counted more than once if they happened to participate in more than one study) and their country of location. Study characteristics, such as sponsor type, blinding, type of randomisation and intervention, and baseline participant characteristics, were also extracted as part of an associated project to compare the characteristics of enrolled study participants versus the dialysis registry population. The results of this project are presented elsewhere ${ }^{4}$ and the study protocol is registered online (PROSPERO ID: CRD42018090862).

The primary outcome of this study was a novel measure of the representation of each global region in RCTs, developed specifically for the present analysis and hereafter referred to as the 'representation index' (RI). This unit-less ratio is defined by the proportion of trial sites identified in each global region (number of trial sites in a global region divided by the total number of trial sites identified worldwide) divided by the proportion of dialysis patients in that region (number of dialysis patients in that region divided by total number of patients receiving dialysis worldwide). The number of dialysis patients worldwide and in each ISN region was derived from the estimates published by Liyanage $e t a l .^{1}$ The supplementary appendix to that publication provided the actual or estimated number of patients receiving dialysis in 2010 for 202 countries. The number of dialysis patients in each ISN global region was the sum of the estimate for each country in that region and the total global dialysis population was the sum of each global region. The ratio of the trial site and population proportions results in an index, where 1.0 indicates that the number of trial sites is proportional to the number of dialysis patients in that region. An RI $>1.0$ indicates relative over-representation and $<1.0$, under-representation in large multicentre studies. The RI was reported for each of the 10 ISN regions.

Two exploratory analyses were performed to examine the relationship between RI and per capita gross domestic product (GDP). This was analysed using linear regression. GDP (in US\$) and population data for 2010 were obtained from the World Bank. ${ }^{5}$ The change over time was analysed by comparing the number of RCTs recruiting from each region in the first half of the decade (2007-2011) to that in the second half of the decade (2012-2016) using exact logistic regression. Statistical analysis was conducted using Stata V.15.0.

\section{Patient and public involvement}

Patients were not directly involved in the design or conduct of this research.

\section{RESULTS}

From the 5229 records retrieved, 180 studies enrolling 76127 participants from 6172 sites were identified for inclusion in the final analysis (figure 1, online supplementary table S1). The majority of studies were conducted 


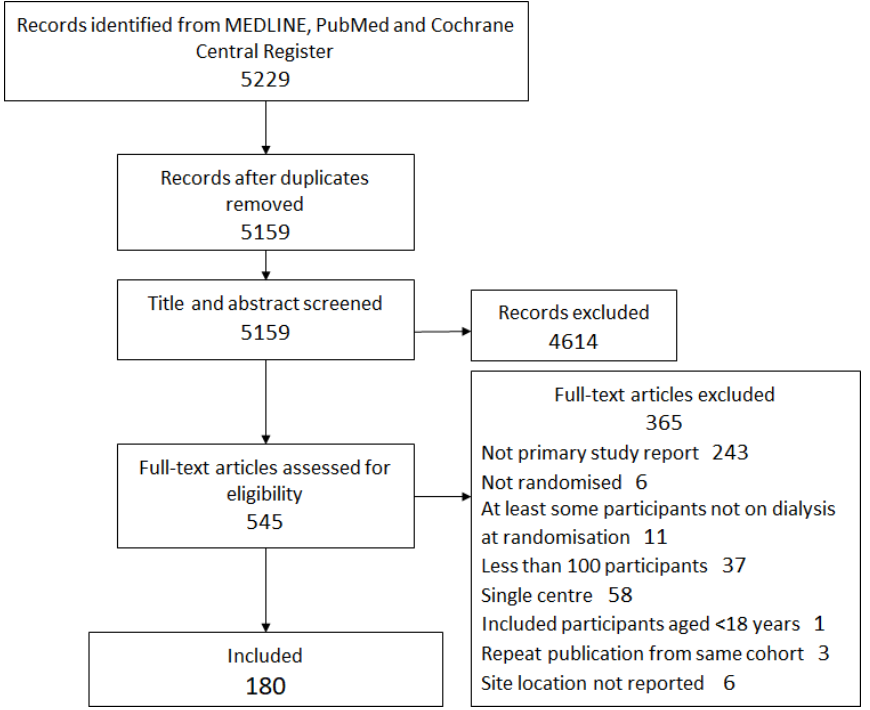

Figure 1 Study selection.

in a single country only $(75.0 \%)$. Study characteristics are presented in table 1 . The median number of participants was 208 (interquartile interval (IQI) 148-334) and the median number of sites was 15 (IQI 5-38). The USA accounted for $41.9 \%$ of sites with no other single country accounting for more than $10 \%$ of sites (online supplementary table S2). After North America with $44.5 \%$ of sites, Western Europe accounted for $26.9 \%$ of sites, followed by North-East Asia with $13.0 \%$ (table 2). Africa and South Asia had the lowest number of sites, accounting for only $0.2 \%$ and $0.3 \%$ of sites, respectively.

\begin{tabular}{lc}
\hline Table 1 Study characteristics & \\
\hline Study characteristic & N (\%) (n=180) \\
\hline Sponsor & $90(50.0)$ \\
\hline Commercial & $81(45.0)$ \\
\hline Non-commercial & $9(5.0)$ \\
$\quad$ Unknown & $164(91.1)$ \\
Type of study & $11(6.1)$ \\
\hline Parallel group & $5(2.8)$ \\
\hline Cluster & $45(25.0)$ \\
\hline $\begin{array}{l}\text { Crossover } \\
\text { Multicountry }\end{array}$ & $7(3-11)$ \\
\hline $\begin{array}{l}\text { Number of countries in multicountry } \\
\text { studies - median (IQR) }\end{array}$ & $147(81.7)$ \\
\hline Included modality & $17(9.4)$ \\
\hline $\begin{array}{l}\text { Haemodialysis } \\
\text { Both hemodialysis and peritoneal } \\
\text { dialysis }\end{array}$ & $16(8.9)$ \\
\hline $\begin{array}{l}\text { Peritoneal dialysis } \\
\text { Number of participants - median (IQR) }\end{array}$ & $208(148-334)$ \\
\hline Number of sites - median (IQR) & $15(5-38)$ \\
\hline $\begin{array}{l}\text { Planned duration of follow-up (months) - } \\
\text { median (IQR) }\end{array}$ & $7(3-12)$ \\
\hline
\end{tabular}

Data from Liyanage et al resulted in an estimate of 2047471 dialysis recipients in 2010. The largest share of these patients was from North-East Asia $(31.3 \%, 639$ 901), followed by North America $(21.6 \%, 443139)$ and Western Europe $(12.2 \%, 249$ 671) (table 2). Using these estimates and the site numbers to determine the RI, four regions were identified as well-represented $(\mathrm{RI}>1)$ and six were under-represented $(\mathrm{RI}<1)$ (table 2$)$. As seen in figure 2, the highest representation was in Eastern and Central Europe with an RI of 2.45, with $6.9 \%$ of the large multicentre study sites from an estimated $2.8 \%$ of the global dialysis population. Six regions were underrepresented, with the lowest being 0.05 for Africa with only $0.2 \%$ of study sites from $4.0 \%$ of the global dialysis population (table 2). For every US\$10000 in per capita GDP, the RI increased by 0.42 (95\% CI 0.08 to 0.76 , $\mathrm{p}=0.022$ ) (figure 3). This relationship explained half of the observed variation in RI (R-squared $=0.50$ ).

The number of RCTs recruiting from each region in the first and second halves of the decade (2007-2016) is compared in figure 4. Growth in the proportion of studies with sites in the region was greatest in the Middle East (OR 6.36 (95\% CI 0.87 to 282.2), $\mathrm{p}=0.08$ ), although the numbers in this region were small (1 vs. 10 studies) and the change did not reach significance. This was followed by North-East Asia (OR 2.23 (95\% CI 1.06 to $4.89), \mathrm{p}=0.03)$, which also recorded the largest numerical growth (14 vs. 42 studies). All other under-represented regions saw a relative decline in the proportion of studies including sites from that region.

\section{DISCUSSION}

This data clearly show extraordinary differences between global regions in terms of dialysis patient participation in large, multicentre RCTs-those RCTs most likely to provide a firm foundation for evidence-based practice. These differences are perhaps unsurprising as they parallel the long-standing disparities in income between global regions. However, they do highlight a number of areas of concern given that the number of dialysis patients is growing globally and in excess of economic growth. Growth in dialysis patients is particularly fast in Asia, with growth in demand for dialysis exceeding $10 \%$ per year in China, the Philippines and Malaysia, and over $30 \%$ per year in India. ${ }^{6}$ Many regions with rapid growth in ESKD populations are also those found to be underrepresented in large clinical trials.

The causes of the growth in the global dialysis population are complex, but include a commitment by a number of state governments to providing dialysis care within government-funded healthcare programmes. In resource-poor countries, it is particularly important that healthcare spending is effective and clinical research is conducted to inform clinicians and policymakers of the best use of their scarce resources. Much of the research conducted in high-income countries is restricted in its generalisability to countries with distinct populations and 
Table 2 Number of trial sites and patients by ISN region and representation index

\begin{tabular}{lccccc}
\hline & $\begin{array}{l}\text { Number of } \\
\text { sites }\end{array}$ & $\begin{array}{l}\text { Proportion of } \\
\text { sites (\%) }\end{array}$ & $\begin{array}{l}\text { Dialysis } \\
\text { patients } \\
\mathbf{2 0 1 0}^{*}\end{array}$ & $\begin{array}{l}\text { Proportion of } \\
\text { global dialysis } \\
\text { patients (\%) }\end{array}$ & $\begin{array}{l}\text { Representation } \\
\text { indext }\end{array}$ \\
\hline $\begin{array}{l}\text { Eastern and Central } \\
\text { Europe }\end{array}$ & 424 & 6.9 & 57870 & 2.8 & 2.45 \\
$\begin{array}{l}\text { Western Europe } \\
\text { North America }\end{array}$ & 1658 & 26.9 & 249671 & 12.2 & 2.20 \\
$\begin{array}{l}\text { Russia and newly } \\
\text { independent states }\end{array}$ & 2748 & 44.5 & 443139 & 21.6 & 2.06 \\
$\begin{array}{l}\text { South-East Asia and } \\
\text { Oceania }\end{array}$ & 143 & 2.3 & 33830 & 1.7 & 1.36 \\
$\begin{array}{l}\text { North-East Asia } \\
\text { Middle East }\end{array}$ & 161 & 2.6 & 86529 & 4.2 & 0.62 \\
\hline $\begin{array}{l}\text { Latin America and the } \\
\text { Caribbean }\end{array}$ & 802 & 13.0 & 639901 & 31.3 & 0.41 \\
\hline South Asia & 82 & 1.3 & 103124 & 5.0 & 0.27 \\
\hline Africa & 122 & 2.0 & 274205 & 13.4 & 0.15 \\
\hline Total & 19 & 0.3 & 78111 & 3.8 & 0.08 \\
\hline
\end{tabular}

*Liyanage et al (2015). ${ }^{1}$

†Equals proportion of sites divided by the proportion of global dialysis patients. Note: Calculations were performed without the rounding displayed in the table.

ISN, International Society of Nephrology.

healthcare systems. Dialysis practices frequently differ, often driven by resource limitations. Examples include the frequent use of two times per week dialysis (in contrast to the almost ubiquitous three times per week schedules in developed countries) and dialyser reuse. ${ }^{6}$ Cause of ESKD also differs, for example, some regions experience a high burden of chronic interstitial nephropathy (also known as chronic kidney disease of uncertain aetiology). ${ }^{78}$ Furthermore, co-morbid illnesses differ, with a greater prevalence of some infectious diseases, such as hepatitis and tuberculosis, complicating the management of patients with ESKD. ${ }^{6}$ Finally, many low-income and middle-income countries are facing a rising burden of non-communicable diseases in the presence of a

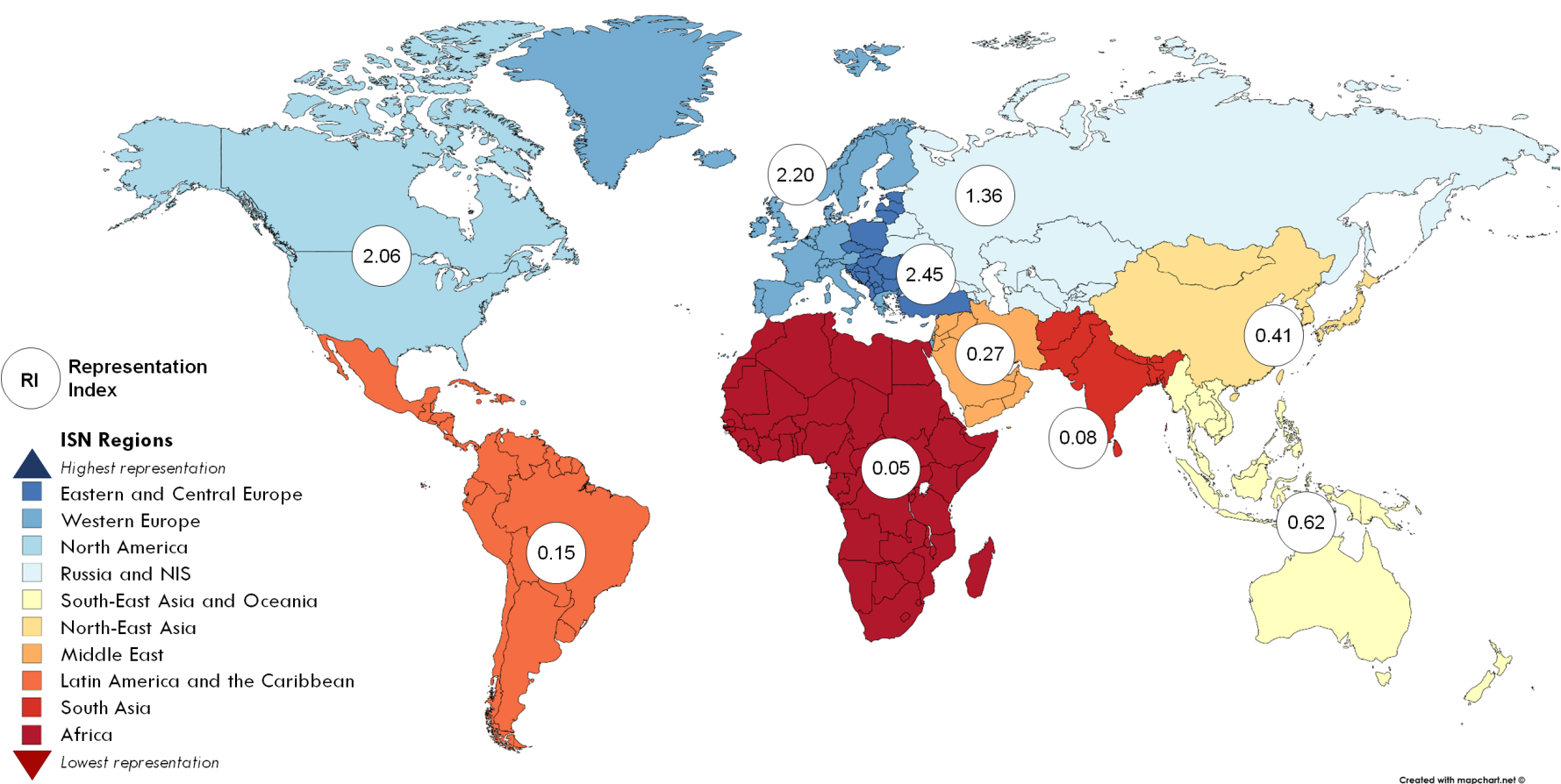

Figure 2 Global representation in large RCTs. ISN, International Society of Nephrology; NIS, newly independent states; RCTs, randomised controlled trials. 


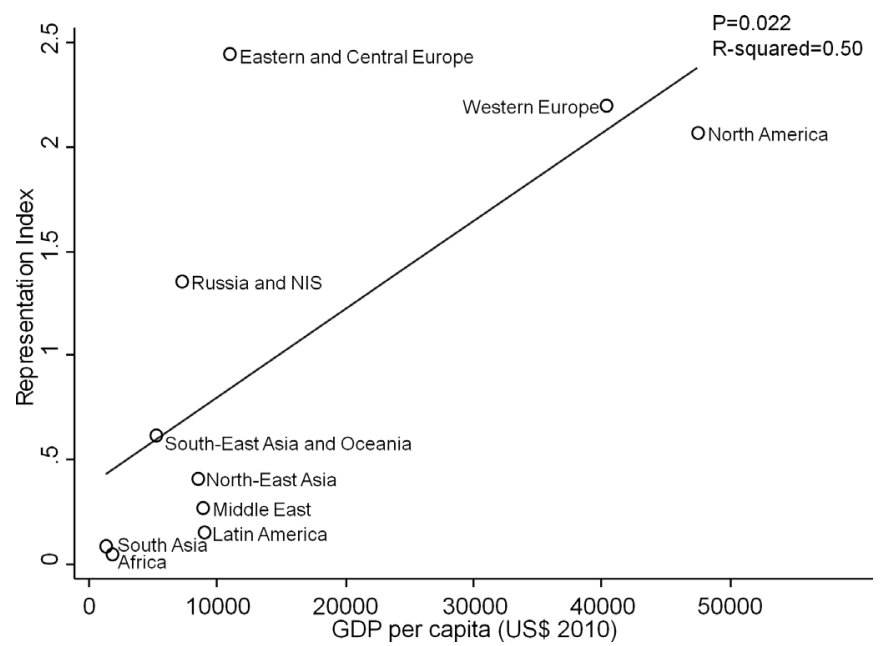

Figure 3 Representation index and per capita gross domestic product (GDP). NIS, newly independent states.

continued need to invest scarce healthcare resources combatting persistently high rates of communicable diseases. ${ }^{2}$ As a result, ESKD may be accorded relatively lower research priority. Yet, dialysis is a resource-intensive therapy and randomised research in the local context may help to ensure effective use of such scarce resources. These factors all underline the importance of locally relevant high-quality evidence.

Our data suggest that the number of large RCTs is growing, particularly in North-East Asia. This growth reflects rapid expansion in medical research funding (public and industry) in Asia, as compared with North
America and Europe. However, reasons for change in RCT participation are undoubtedly complex, as evidenced by the significant reduction in the proportion of RCTs from Western Europe, representing a small real change (33 vs. 27 RCTs) and a large relative change. This is distinct from North America, where the decline was only relative, given a real increase in RCT participation (29 vs. 38 RCTs). At a broader level, annual growth in medical research investment was higher in Europe between 2004 and 2011 than in North America, ${ }^{9}$ but the share of this originating from the public sector was lower ${ }^{10}$ - which could result in different research priorities. Yet, most strikingly, the lack of growth in RCTs recruiting in South Asia, Latin America, the Caribbean and Africa indicates an ongoing need for investment in clinical trial infrastructure. India is a prime example, where the dialysis market is growing explosively, ${ }^{11}$ while up to $90 \%$ of those with ESKD cannot afford KRT and of those who do start dialysis, more than half have to stop due to financial constraints. ${ }^{7}$ Clearly, a larger evidence base supporting the efficacy and costeffectiveness of local practices would be beneficial.

Conducting RCTs in many parts of the world is challenging due to resource scarcity, underdeveloped regulatory infrastructure and cultural differences. The importance of a clear legal and regulatory structure in encouraging larger studies is suggested by the position of Eastern and Central Europe, a region which is better represented than its GDP would predict. One explanation for this may be the legal harmonisation provided by the European Union which facilitates cross-border

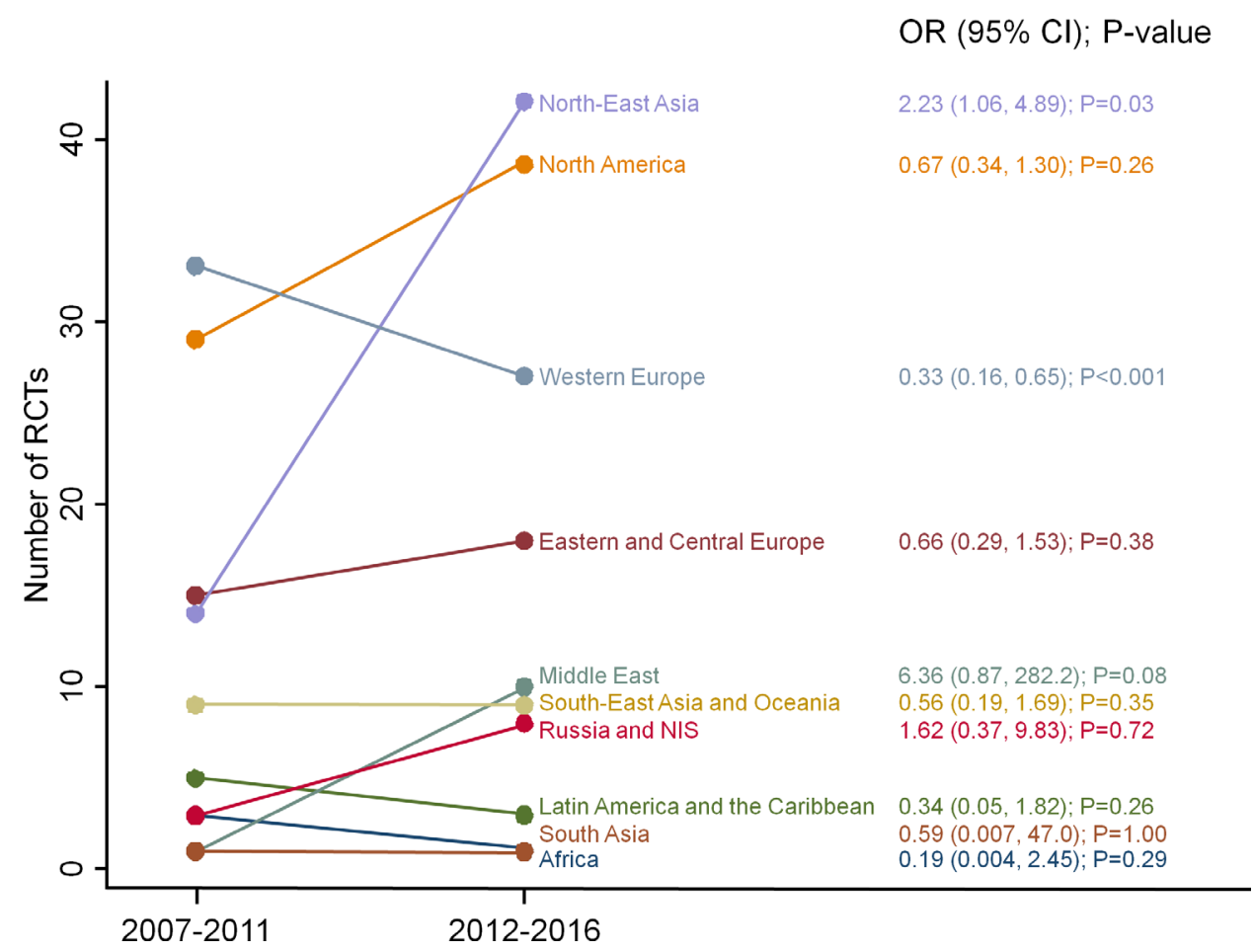

Figure 4 Change in number of RCTs from each ISN region between 2007-2011 and 2012-2016. ORs derived from exact logistic regression and indicate relative odds of an RCT including sites from each ISN region in 2012-2016 compared with 2007-2011. NIS, newly independent states; RCTs, randomised controlled trials. 
collaboration. To this may be added the lower cost of research staff and related activities in Eastern (as compared with Western) Europe. An effort among under-represented countries to ensure national clinical research regulations are clear and that application procedures are simplified (where possible) could be considered as a means for lower-resource countries to attract research investment. Collaboration between different global regions and sharing of expertise may provide advantages for researchers from both high-income and low-middle-income countries. The ISN has recognised this need and is building a network to foster RCTs. ${ }^{12}$

The global disparities identified appear comparable to other disciplines in internal medicine. For instance, Butler et al surveyed all cardiovascular trials in leading journals over a 10-year period and found that, of 1224 trials, $63.5 \%$ recruited only in North America or Western Europe, $7.7 \%$ outside this region and $28.8 \%$ multiregional, suggesting that some global regions may be similarly underserved by cardiovascular trials. ${ }^{13}$ Additionally, that cardiovascular trials were two times the size of those identified in this study (median 452 participants) and recruited from more sites (median 20), suggests that the small size and relative paucity of trials in nephrology remains an ongoing problem, one not entirely explained by resources and infrastructure. ${ }^{14}{ }^{15}$ This is not to say that all trials should recruit patients from multiple global regions, or conversely, that trials should focus recruitment in a single region. Ideally, research networks can continue to develop in a way that permits broad international or regional collaboration as befits the clinical question and resources available for each RCT.

The primary limitation of our study is that we could not establish the country of origin of individual RCT participants. Site size is likely to vary between countries (eg, anecdotally, sites in China are substantially larger than those in Australia), meaning that, were study participation to be measured individually, the relative representation by region may differ. However, site participation is, in itself, a useful measure of the strength of randomised research in a region as each site represents a unit with the skills and resources to participate. Second, our estimates of site number may have been affected by the variability in study reporting of site location. Site numbers were sometimes established from lists of primary investigators in supplementary material, or from site listings on trial registries. We cannot always be sure whether this indicated the number of physical sites or networks of sites. Overall, the fact that establishing the number of sites in a particular country proved challenging at times, and that establishing the number of participants from each country was impossible, is clear evidence of the low priority afforded to generalisability by country or region by many authors and reviewers. Another limitation is that ISN Global Regions are not homogenous and large differences in study participation within regions have not been directly addressed. As we did not include clinical trial registries, regional databases or non-indexed literature in our search strategy, it is possible that some studies have been missed. Finally, our focus on large multicentre studies means that we cannot comment on the growth in smaller or single-centre studies on a global level. This means our results are not a summary of global clinical research activity in dialysis and should not be read as indicating a lack of high-quality researchers in some global regions.

\section{CONCLUSIONS}

This study demonstrated marked regional disparities in site participation in large multicentre RCTs enrolling dialysis patients. These differences may reflect more than simple wealth disparity. While there is evidence of growth in site participation in some regions, other regions, including some with rapidly growing populations of people on dialysis, remain under-represented. A coordinated effort to increase the numbers of large RCTs, including patients from all global regions, is required to ensure that patients and clinicians obtain access to highquality and locally generalisable clinical evidence.

\section{Author affiliations}

${ }^{1}$ Renal and Metabolic Division, The George Institute for Global Health and University of New South Wales, Sydney, New South Wales, Australia

${ }^{2}$ Sydney School of Public Health, University of Sydney, Sydney, New South Wales, Australia

${ }^{3}$ Faculty of Medicine, Vajira Hospital, Navamindradhiraj University, Bangkok, Thailand

${ }^{4}$ Chelsea and Westminster Hospital, London, UK

${ }^{5}$ Department of Nephrology, Princess Alexandra Hospital, Brisbane, Queensland, Australia

${ }^{6}$ Faculty of Medicine, University of Queensland, Brisbane, Queensland, Australia ${ }^{7}$ The George Institute for Global Health, University of Oxford, Oxford, UK ${ }^{8}$ Department of Epidemiology, Johns Hopkins University, Baltimore, Maryland, USA ${ }^{9}$ Department of Renal Medicine, Concord Repatriation General Hospital, Concord, New South Wales, Australia

Acknowledgements The authors thank Dr Ying Xu for her kind assistance with the translation of Chinese manuscripts.

Contributors BS conceived of the study, conducted the analysis and drafted the manuscript. BS, KT and AH performed title and abstract review, plus data extraction. BT assisted with the design of graphics and provided a critical review of the manuscript. $\mathrm{CH}, \mathrm{MW}$, MJ and VP all contributed to the design of the study and provided a critical review of the study protocol and the manuscript.

Funding BS is supported by an Australian Government Research Training Program Scholarship via the University of Sydney.

Map disclaimer The depiction of boundaries on the map(s) in this article do not imply the expression of any opinion whatsoever on the part of BMJ (or any member of its group) concerning the legal status of any country, territory, jurisdiction or area or of its authorities. The map(s) are provided without any warranty of any kind, either express or implied.

Competing interests None declared.

Patient consent for publication Not required.

Provenance and peer review Not commissioned; externally peer reviewed.

Data availability statement Data are available on reasonable request.

Open access This is an open access article distributed in accordance with the Creative Commons Attribution Non Commercial (CC BY-NC 4.0) license, which permits others to distribute, remix, adapt, build upon this work non-commercially, and license their derivative works on different terms, provided the original work is properly cited, appropriate credit is given, any changes made indicated, and the use is non-commercial. See: http://creativecommons.org/licenses/by-nc/4.0/. 
ORCID iD

Brendan Smyth http://orcid.org/0000-0003-1838-3348

\section{REFERENCES}

1 Liyanage T, Ninomiya T, Jha V, et al. Worldwide access to treatment for end-stage kidney disease: a systematic review. Lancet 2015;385:1975-82.

2 Smyth B, Knight JF, Herrington WG. The rise and rise of randomized clinical evidence in sub-Saharan Africa. Clin Kidney J 2016;9:814-6.

3 Rothwell PM. External validity of randomised controlled trials: "to whom do the results of this trial apply?". Lancet 2005;365:82-93.

4 Smyth B, Haber A, Trongtrakul K, et al. Representativeness of randomized clinical trial cohorts in end-stage kidney disease: a meta-analysis. JAMA Intern Med 2019.

5 The World Bank Group. World Bank national accounts data, and OECD National Accounts data files GDP (2010 US\$), 2018. Available: https://data.worldbank.org/indicator/NY.GDP.MKTP.KD? end=2011\&start $=2010$

6 Prasad N, Jha V. Hemodialysis in Asia. Kidney Dis 2015;1:165-77.

7 Varughese S, Abraham G. Chronic kidney disease in India: a clarion call for change. Clin J Am Soc Nephrol 2018;13:802-4.
8 Jayasekara KB, Dissanayake DM, Sivakanesan R, et al. Epidemiology of chronic kidney disease, with special emphasis on chronic kidney disease of uncertain etiology, in the North central region of Sri Lanka. J Epidemiol 2015;25:275-80.

9 Moses H. 3Rd, Matheson DH, Cairns-Smith S, et al. The anatomy of medical research: US and international comparisons. Jama 2015;313:174-89.

10 Bouillon R, Slordahl S, Nogueira MM, et al. Public investment in biomedical research in Europe. Lancet 2015;386:1335.

11 Pacific Bridge Medical. India's Dialysis Market, 2013. Available: https://www.pacificbridgemedical.com/publication/high-rates-ofchronic-kidney-disease-lead-to-medtech-opportunities-in-india/

12 International Society of Nephrology. International Society of Nephrology-Advancing clinical trials (ISN-ACT), 2019. Available: https://www.theisn.org/research/isn-act

13 Butler J, Tahhan AS, Georgiopoulou VV, et al. Trends in characteristics of cardiovascular clinical trials 2001-2012. Am Heart J 2015;170:263-72.

14 Inrig JK, Califf RM, Tasneem A, et al. The landscape of clinical trials in nephrology: a systematic review of ClinicalTrials.gov. Am J Kidney Dis 2014:63:771-80.

15 Strippoli GFM, Craig JC, Schena FP. The number, quality, and coverage of randomized controlled trials in nephrology. J Am Soc Nephrol 2004;15:411-9. 